\title{
Process Safety Across the Chemical Engineering \\ Curriculum
}

Supporting Information: Worked Example of a

Safety Module

\author{
H. Scott Fogler, * Laura J. Hirshfield \\ Department of Chemical Engineering
}

The University of Michigan

2300 Hayward Street

Ann Arbor, Michigan 48109-2136 
Problem Statement: It was a hot day in St. Louis, $96^{\circ} \mathrm{F}\left(35.9^{\circ} \mathrm{C}\right)$, where Praxair had set cylinders with flammable gases on hot black asphalt pavement. Direct sunlight and radiant heat from the asphalt pavement ${ }^{1}$ heated the propylene cylinders.

The vapor pressure in a liquid propylene cylinder exceeded a faulty set pressure on the cylinder's relief valve that was too low, and propylene escaped into the yard. The resulting vapor plume found an ignition source and a fire started. The fire heated nearby acetylene and liquefied petroleum gas (LPG) cylinders and they in turn released more flammable gases, which enlarged the fire.

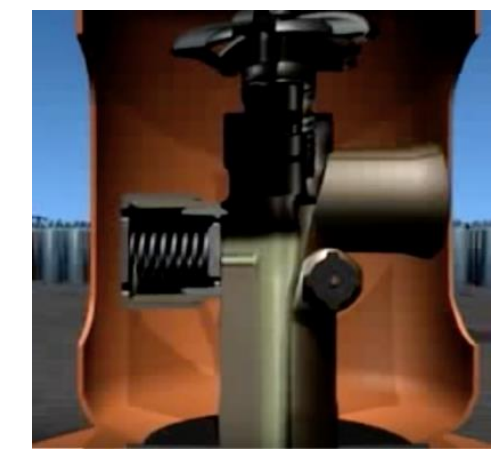

Pressure relief valve - cut away

Watch the Video: (https://www.youtube.com/watch? $v=-Z L Q k n 7 X-k)^{2}$

Incident Report Available At: (https://www.csb.gov/file.aspx?DocumentId $=5642)^{3}$ (pages 1-10)

\section{Solution:}

(a) It is important that chemical engineers have an understanding of what the accident was, why it happened and how it could have been prevented in order ensure similar accidents may be prevented. Applying a safety algorithm to the accident will help achieve this goal. In order to become familiar with a strategy for accident awareness and prevention, view the Chemical Safety Board video on the Praxair flammable gas fires and explosion and fill out the following algorithm. See definitions on the last page. If necessary, view pages 1-10 of the incident report.

\section{Safety Analysis of the Incident}

Activity: The activity in this incident is the storage of propylene cylinders outdoors in the sun during high heat weather.

Hazard: The hazard in this incident is the flammability of propylene.

Incident: The incident was the pressure in the storage tanks reaching the set point, which vented the propylene gas out to relieve the pressure. This release of the flammable gas then led to the explosion at the Praxair facility. This explosion resulted in fire and other damage to the surrounding community. 
Initiating Event: The initiating event in this scenario was the release of propylene due to the increase of pressure in the storage cylinders.

Preventative Actions and Safeguards: Some preventative actions or safeguard include the revision of safety standards for relief valves, routine inspection/maintenance of set points on the relief valves, provide shade for the cylinders stored outside, place the cylinders farther apart from one another in storage yard, inspect the cylinders to determine if there is any liquid propylene within, and provide a cooling system to the storage area.

Contingency Plan/Mitigating Actions: Some mitigating actions include installation of fire protection systems and gas release detectors to notify when gas has been released, place cylinders farther apart from one another and barriers to contain exploding cylinders.

Lessons Learned: The lesson learned from this incident was that many pressure relief valves are susceptible to mechanical failure that results in lowered set pressures that can be reached during hot summer days.

The air temperature reached $96^{\circ} \mathrm{F}\left(36.9^{\circ} \mathrm{C}\right)$ at $2 \mathrm{p} . \mathrm{m}$. and the asphalt surface was approximately $140^{\circ} \mathrm{F}(333 \mathrm{~K})$ causing the cylinder temperature to be at least $135^{\circ} \mathrm{F}(330 \mathrm{~K})$.

\section{Additional information}

Propylene boils at $225.6 \mathrm{~K}$ at $1 \mathrm{~atm}(101.3 \mathrm{kPa})$. The heat of vaporization is $18.4 \mathrm{~kJ} / \mathrm{mol} \mathrm{R}=8.314$ $\mathrm{J} / \mathrm{mol} \cdot \mathrm{K}$, the critical pressure and temperature are $\mathrm{P}_{\mathrm{C}}=4.0 \mathrm{MPa}$ and $\mathrm{T}_{\mathrm{C}}=364.9 \mathrm{~K}$ respectively, and the vapor molar volume of propylene is $2.13 \cdot 10^{-3} \mathrm{~m}^{3} / \mathrm{mol}$

(b) Use the ideal gas law to estimate the pressure, $\mathrm{P}$, inside the cylinder at $25^{\circ} \mathrm{C}$ and at $57^{\circ} \mathrm{C}(330$ $\mathrm{K})$ when there is only propylene gas.

$$
\begin{gathered}
P \underline{V}=R T \\
P\left(25^{\circ} \mathrm{C}\right)=\frac{R T}{\underline{V}}=\frac{\left(8.314 \mathrm{~m}^{3} \cdot \mathrm{Pa} / \mathrm{mol} \cdot \mathrm{K}\right) \cdot(298 \mathrm{~K})}{2.13 \cdot 10^{-3} \mathrm{~m}^{3} / \mathrm{mol}} \\
P\left(25^{\circ} \mathrm{C}\right)=1163179.34 \mathrm{~Pa}=1.16 \mathrm{MPa} \\
P\left(57^{\circ} \mathrm{C}\right)=\frac{R T}{\underline{V}}=\frac{\left(8.314 \mathrm{~m}^{3} \cdot \mathrm{Pa} / \mathrm{mol} \cdot \mathrm{K}\right) \cdot(330 \mathrm{~K})}{2.13 \cdot 10^{-3} \mathrm{~m}^{3} / \mathrm{mol}} \\
P\left(57^{\circ} \mathrm{C}\right)=1288084.51 \mathrm{~Pa}=1.29 \mathrm{MPa}
\end{gathered}
$$

(c) Assuming vapor liquid equilibrium estimate the pressure, $\mathrm{P}$, in the cylinder at $25^{\circ} \mathrm{C}$ and at $57^{\circ} \mathrm{C}$ using

(1) The Clausius-Clapeyron equation 


$$
\begin{aligned}
& \ln \left(\frac{P}{P_{\text {sat }}}\right)=\frac{-H_{\text {vap }}}{R}\left(\frac{1}{T}-\frac{1}{T_{\text {sat }}}\right) \\
& \ln \left(\frac{P}{0.101 \mathrm{MPa}}\right)=\frac{-18400 \mathrm{~J} / \mathrm{mol} \cdot \mathrm{K}}{8.314 \mathrm{~J} / \mathrm{mol} \cdot \mathrm{K}}\left(\frac{1}{298 \mathrm{~K}}-\frac{1}{225.6 \mathrm{~K}}\right) \\
& P\left(25^{\circ} \mathrm{C}\right)=1.09 \mathrm{MPa} \\
& \ln \left(\frac{P}{0.101 \mathrm{MPa}}\right)=\frac{-18400 \mathrm{~J} / \mathrm{mol} \cdot \mathrm{K}}{8.314 \mathrm{~J} / \mathrm{mol} \cdot K}\left(\frac{1}{330 \mathrm{~K}}-\frac{1}{225.6 \mathrm{~K}}\right) \\
& P\left(57^{\circ} \mathrm{C}\right)=2.25 \mathrm{MPa}
\end{aligned}
$$

(2) The short cut equation where $\omega$ is the acentric factor, with $\omega=0.142$ for propylene

$$
\begin{gathered}
\log _{10}\left(\frac{P}{P_{C}}\right)=\frac{7}{3}(\omega+1)\left(1-\frac{T_{C}}{T}\right) \\
\log _{10}\left(\frac{P}{P_{C}}\right)=\frac{7}{3}(0.142+1)\left(1-\frac{364.9 \mathrm{~K}}{298 \mathrm{~K}}\right) \\
P / P_{C}=0.253 \\
P\left(25^{\circ} \mathrm{C}\right)=P_{r} \cdot P_{C}=0.253 \cdot 4.6 \mathrm{MPa}=1.164 \mathrm{MPa} \\
\log _{10}\left(\frac{P}{P_{C}}\right)=\frac{7}{3}(0.142+1)\left(1-\frac{364.9 \mathrm{~K}}{330 \mathrm{~K}}\right) \\
P / P_{C}=0.523 \\
P\left(57^{\circ} \mathrm{C}\right)=P_{r} \cdot P_{C}=0.523 \cdot 4.6 \mathrm{MPa}=2.41 \mathrm{MPa}
\end{gathered}
$$

(d) Plot Pressure, $\mathrm{P}$, as a function of Temperature, T, using the ideal gas law, the ClausiusClapeyron equation and the short cut equation from $25^{\circ} \mathrm{C}$ to $67^{\circ} \mathrm{C}$ on the same figure and then write a conclusion. 


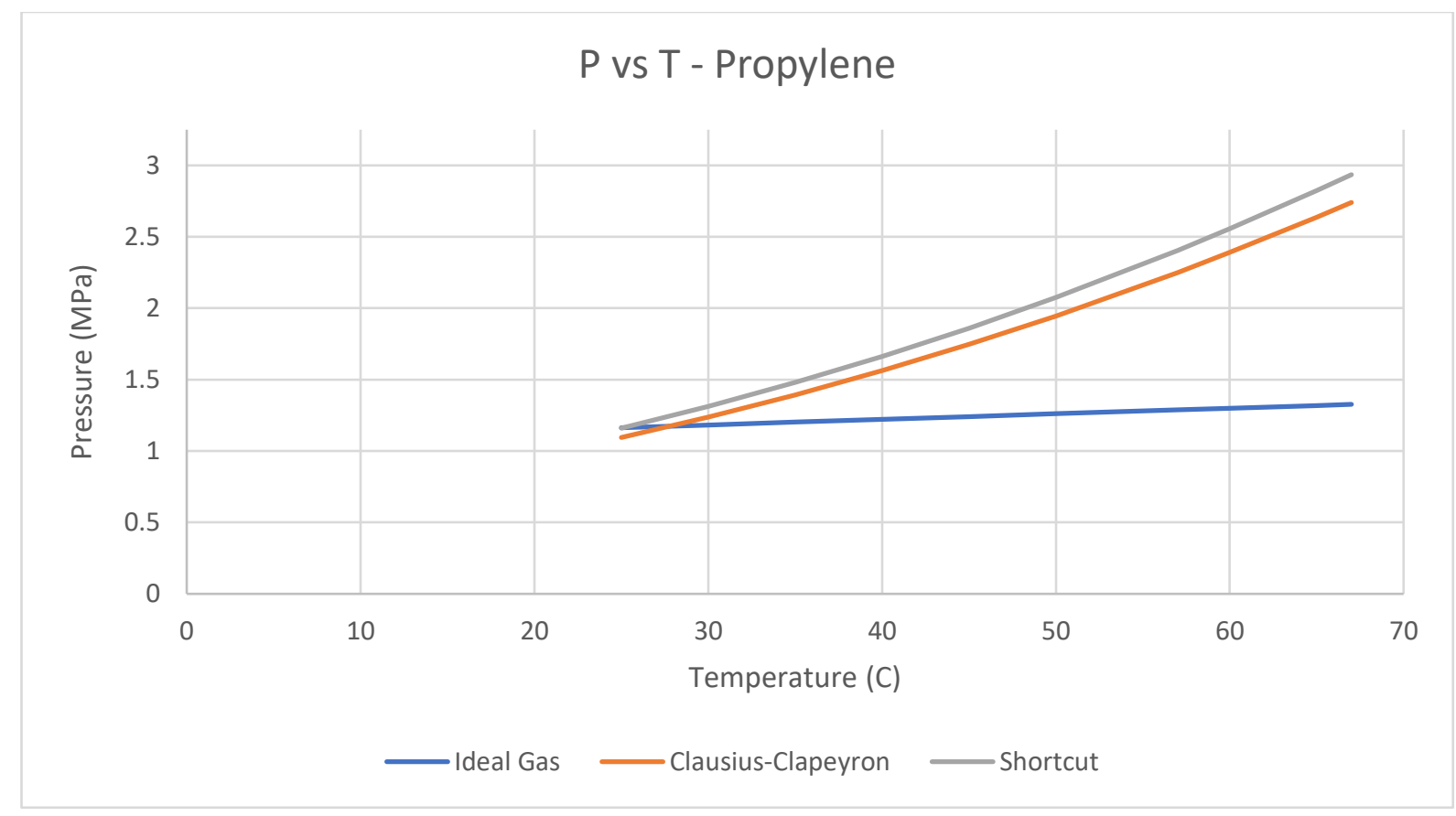

\section{Conclusion:}

The shortcut equation is the most accurate model for this system since the shortcut is a modified version of the Clausius-Clapeyron to account for a non-ideal gas, which is the case here since the pressure is too high to assume ideal gas behavior.

If the employees were to use the ideal gas law to estimate the pressure inside the propylene tanks, they would have never been able to predict the release of gas from the tanks because the linear relationship does not model the dramatic increase of pressure that occurs due to extreme heat.

(e) Review the information in the NFPA Diamond tutorial (http://umich.edu/ safeche/nfpa.html). After reviewing the information, visit the CAMEO Chemicals website (https://cameochemicals.noaa.gov/) and fill out the blank NFPA Diamond to the right for propylene.

Propylene: https://cameochemicals.noaa.gov/chemical/4355

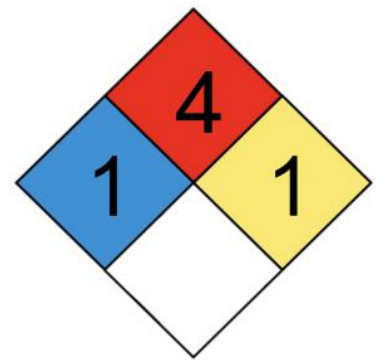

Propylene is highly flammable. A moderate concentration of propylene can cause dizziness, drowsiness, and unconsciousness. Contact with liquefied propylene can cause frost bite. When mixed with hot water, a superheated explosion may occur.

(f) Review the explanation of the components of a bow-tie diagrams found on the safety website (http://umich.edu/ safeche/bowtie.html). After reviewing the information, create a bow-tie diagram for the Praxair incident. 


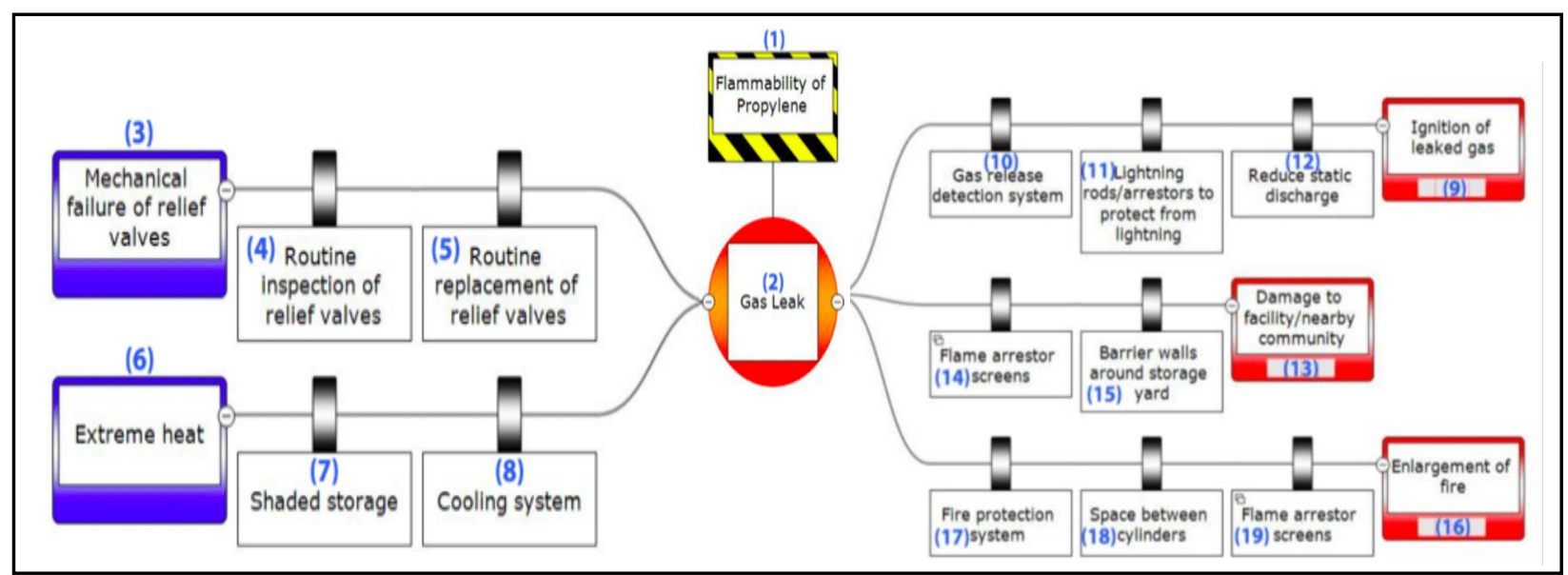

(g) Describe what was the most unsettling to you about the incident.

\section{Wolfram}

Click http://www.wolfram.com/cdf-player/ to download Wolfram CDF Player for free.

Click http://umich.edu/ safeche/assets/pdf/courses/codes/CDF installation tutorial.pdf to view CDF installation tutorial.

Click http://umich.edu/ safeche/assets/pdf/courses/codes/Mass\&Heat(2)HerrigPropane 1.zip.zip to download Wolfram CDF code for this module.

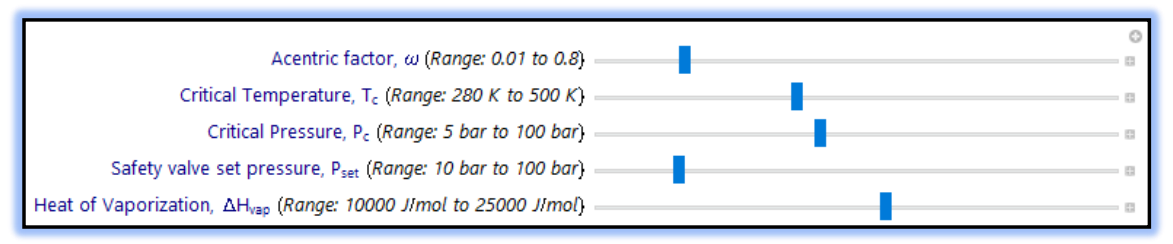

Figure 1.1 Wolfram Sliders 


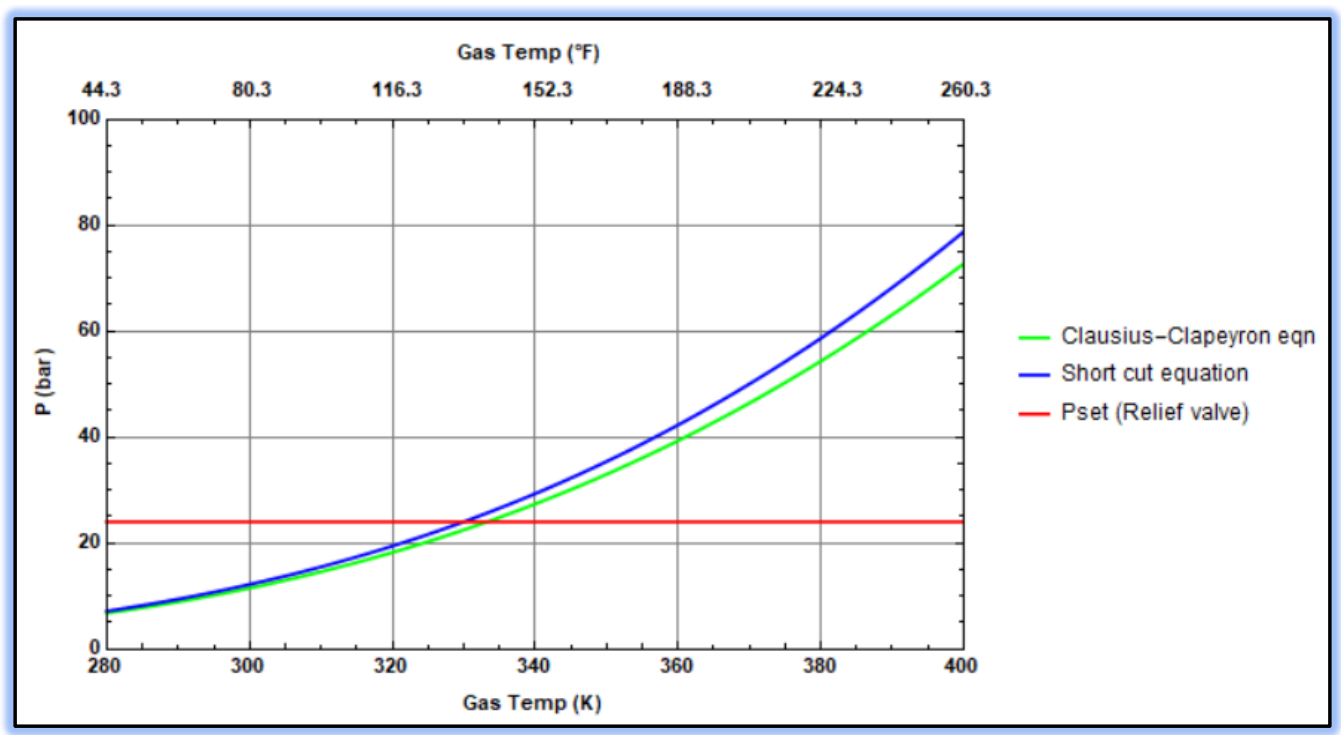

Figure 1.2: Vapor pressure vs. temperature

(i) Refer to the Wolfram plot of vapor pressure vs. temperature obtained using the shortcut equation. Find the minimum set pressure such that the explosion could have been prevented. Assume that the explosion occurred at a temperature of $135^{\circ} \mathrm{F}(330 \mathrm{~K})$. Vary the slider for set pressure and describe how maximum allowable temperature varies with increasing set pressure.

At $330 \mathrm{~K}$, the vapor pressure obtained using the shortcut equation is 24.1 bar. Hence, for a safe operation, the set pressure should have been at least 26 bar. According to the incident report, the minimum set pressure should have been 390 psi ( 26.8 bar). Therefore, had it been set correctly, the explosion could have easily been prevented.

If temperature is $300 \mathrm{~K}$, the vapor pressure of the gas is $\sim 13$ bar. Hence a safe value of set pressure should be 15-20 bar. Alternatively, if the set pressure is 15 bar, then maximum allowable temperature is $300 \mathrm{~K}$. At $380 \mathrm{~K}$, the vapor pressure is $\sim 60$ bar. Hence, a safe value of set pressure will be 65-70 bar. For a higher temperature, vapor pressure is greater, and hence, a higher set pressure is advisable. If it is known that the gas will not reach very high temperatures, then lower pressures can be set.

(ii) What is the required set pressure if you use the Clausius Clapeyron Equation with $\Delta H_{v a p}=15 \mathrm{~kJ} / \mathrm{mol}$ ? Is this set pressure more or less than that obtained in (i)? Vary the $\Delta \mathrm{H}_{\mathrm{vap}}$ slider to check at what value of $\Delta \mathbf{H}_{\text {vap }}$ the Clausius Clapeyron Equation agrees with the shortcut equation (within 3\%). Can you give an explanation for the discrepancy between the pressures calculated by the two equations?

At $\Delta \mathrm{H}_{\mathrm{vap}}=15 \mathrm{~kJ} / \mathrm{mol}$, the pressure calculated from the Clausius Clapeyron Equation is less than that using the shortcut equation. 
At $\Delta \mathrm{H}_{\text {vap }}=18.75 \mathrm{~kJ} / \mathrm{mol}$, the Clausius Clapeyron Equation agrees with the shortcut equation.

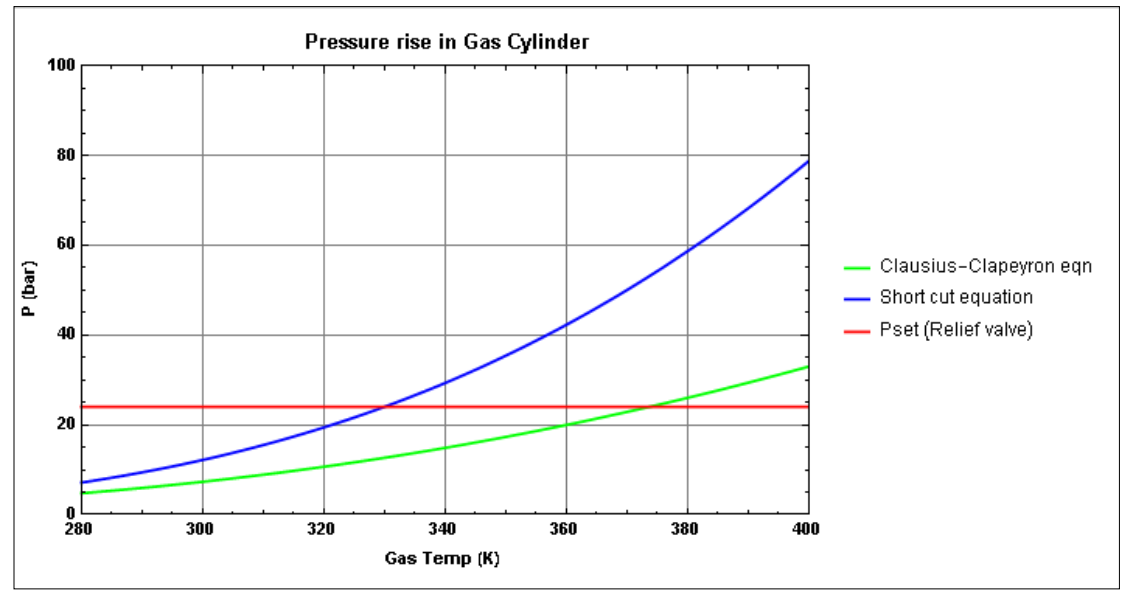

In the shortcut equation, the parameters $\mathrm{P}_{\mathrm{c}}, \mathrm{T}_{\mathrm{c}}$ and $\omega$ are properties of the gas and do not change with temperature. However, $\Delta \mathrm{H}_{\text {vap }}$ is used in the Clausius-Clapeyron equation, which is temperature dependent, and thus must be chosen according to the temperature of the gas. Further, when using the Clausius-Clapeyron equation, the temperature difference between the reference temperature and the temperature of gas should be small, such that $\Delta \mathrm{H}_{\text {vap }}$ remains constant in that small range of temperature. But in the case of $\Delta \mathrm{H}_{\text {vap }}=15 \mathrm{~kJ} / \mathrm{mol}$, the temperature difference is large, and hence there is a discrepancy between the Clausius Clapeyron and Shortcut equations.

(iii) Describe how the vapor pressure - temperature curve (for the shortcut equation) changes when propane is changed to butane or ethane. Vary the sliders for $P_{\text {set }}$ and $\Delta H_{\text {vap }}$ and describe what you find. Are there any generalizations that you can make?

(Hint: use the additional information below)

The vapor pressure of ethane is greater than propane, so the pressure within the vessel exceeds the set pressure at a temperature much lower than $330 \mathrm{~K}$. 


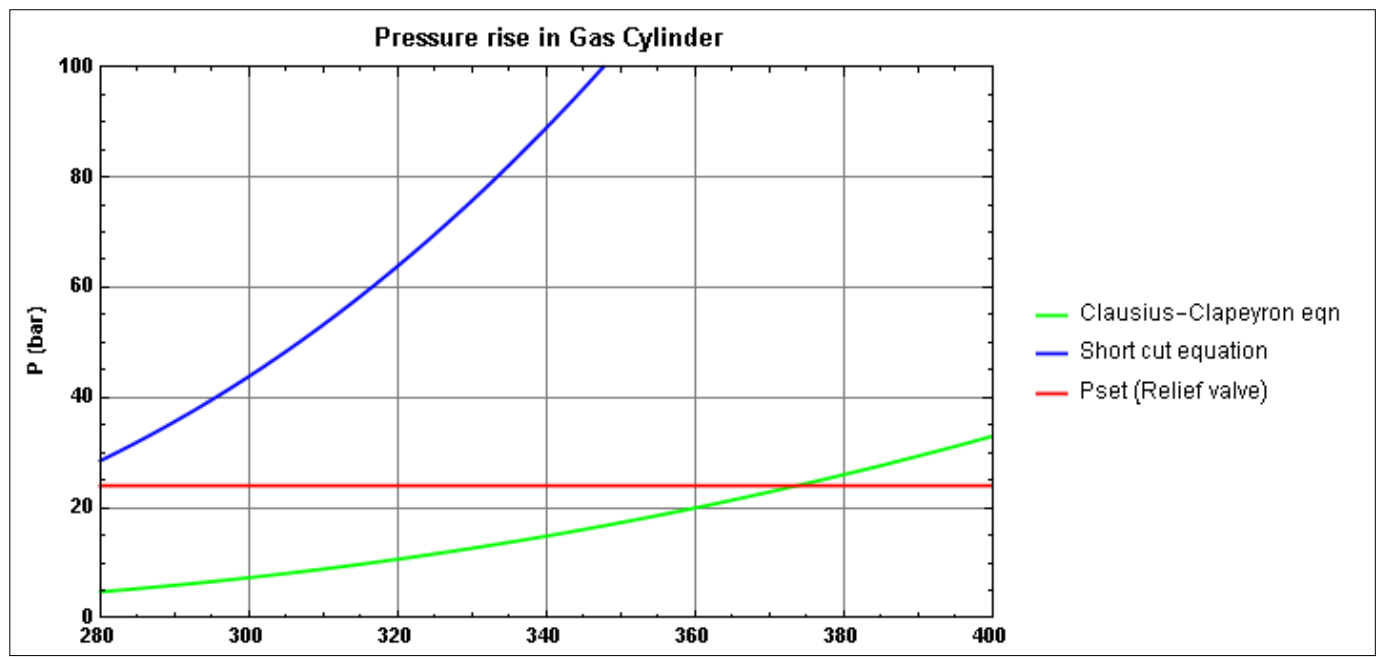

On the other hand, the vapor pressure of butane is much lower than propylene. Even at higher temperatures such as $380 \mathrm{~K}$, the vessel pressure doesn't exceed the set pressure.

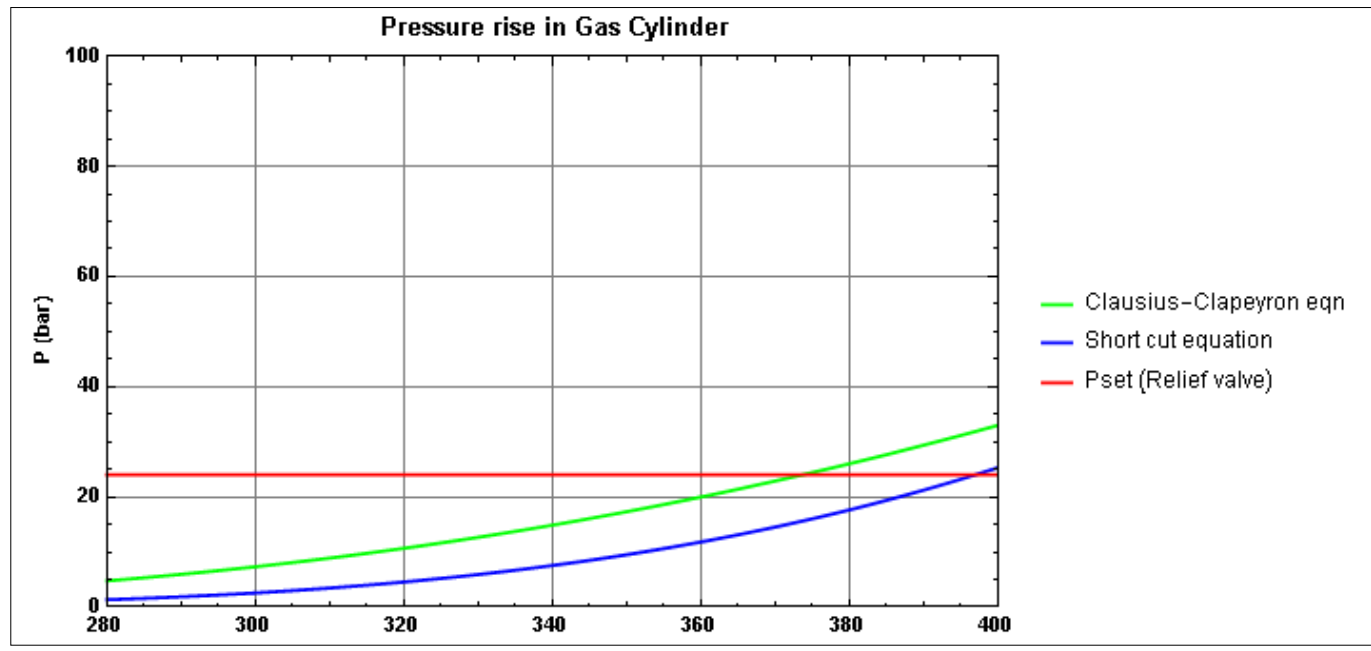

Heavier molecules tend to have a lower vapor pressure, and thus are safer at higher temperatures.

\section{(iv) Write a set of conclusions based on your experiments (i) through (iii)}

Heavier molecules tend to have a lower vapor pressure, and thus are safer at higher temperatures. On the other hand, lighter molecules have a higher vapor pressure, and thus pose a risk even if there are small temperature fluctuations within the vessel.

It is extremely important that the set pressure of relief valves is set correctly; a proper set point can help in reducing the risk of leakage and possible explosion. Gas cylinders should not be kept at very high temperatures so that explosions can be prevented.

\section{Additional Information:}


Parameters of shortcut equation for

Ethane:

$\mathrm{T}_{\mathrm{c}}=305.4 \mathrm{~K}, \mathrm{P}_{\mathrm{c}}=48.8$ bar, $\omega=0.099$

Butane:

$\mathrm{T}_{\mathrm{c}}=425.2 \mathrm{~K}, \mathrm{P}_{\mathrm{c}}=38.0 \mathrm{bar}, \omega=0.199$

Table 1.1 Nomenclature

\begin{tabular}{|c|c|c|}
\hline Symbol & Description & Unit \\
\hline $\mathrm{T}_{\mathrm{c}}$ & Critical temperature & $\mathrm{K}$ \\
\hline $\mathrm{P}_{\mathrm{c}}$ & Critical pressure & $\mathrm{bar}$ \\
\hline$\omega$ & Acentric factor & --- \\
\hline$\Delta \mathrm{H}_{\text {vap }}$ & Enthalpy of vaporization & $\mathrm{kJ} / \mathrm{mol}$ \\
\hline
\end{tabular}

\section{REFERENCES}

(1) Guan, K. K. Surface and Ambient Air Temperatures Associated with Different Ground Material: A Case Study at the University of California, Berkeley; 2011.

(2) CSB Safety Video: Dangers of Propylene Cylinders https://www.youtube.com/watch?v=_ZLQkn7X-k (accessed February 9, 2021).

(3) U.S. Chemical Safety and Hazard Investigation Board. Safety Bulletin: Fire at Praxair St. Louis Dangers of Propylene Cylinders in High Temperatures; 2006. 